\title{
VESTIBOLOGY
}

\section{Saccades and driving}

\section{Saccadi e guida}

\author{
G. GUIDETTI'1 , R. GUIDETTI' ${ }^{1}$ MAURIZIO MANFREDI ${ }^{1}$, MARCO MANFREDI ${ }^{1}$, A. LUCCHETTA², S. LIVIO ${ }^{3}$ \\ ${ }^{1}$ Vertigo Center, Poliambulatorio Chirurgico Modenese, Modena, Italy; ${ }^{2}$ GPS Brain Training Project, Modena, Italy; \\ ${ }^{3}$ Professional Motor Coach, Modena, Italy
}

\begin{abstract}
SUMMARY
Driving is not only a physical task, but is also a mental task. Visual inputs are indispensable in scanning the road, communicating with other road users and monitoring in-vehicle devices. The probability to detect an object while driving (conspicuity) is very important for assessment of driving effectiveness, and correct choice of information relevant to the safety of driving determines the efficiency of a driver. Accordingly, eye fixation and eye movements are essential for attention and choice in decision making. Saccades are the most used and effective means of maintaining a correct fixation while driving. In order to identify the features of the most predisposed subjects at high driving performances and those of the high-level sportsmen, we used a special tool called Visual Exploration Training System. We evaluated by saccade and attentional tests various groups of ordinary drivers, past professional racing drivers, professional truck drivers and professional athletes. Males have faster reaction time compared to females and an age below 30 seems to guarantee better precision of performance and accuracy in achieving all visual targets. The effect on physical activity and sports is confirmed. The performances of the Ferrari Driver Academy (FDA) selected students who were significantly better than those of a group of aspiring students and amateur racing drivers probably thanks to individual predisposition, training and so-called 'neural efficiency'.
\end{abstract}

KEY WORDS: Saccades • Driving • Racecar driver • Eye-tracking $\bullet$ High-level sportsmen

\section{RIASSUNTO}

Guidare non è solo un compito fisico, ma anche mentale. Gli input visivi sono indispensabili per la scansione della strada, la comunicazione con gli altri utenti della strada e il monitoraggio dei dispositivi di bordo. La probabilità di rilevare un oggetto mentre si guida (conspicuity) è molto importante per la valutazione dell'efficacia della guida e la scelta corretta delle informazioni rilevanti per la sicurezza determina l'efficienza di un conducente. Di conseguenza la fissazione visiva e il movimento degli occhi sono essenziali per l'attenzione e la scelta nel prendere decisioni. I movimenti saccadici sono il mezzo più usato ed efficace per mantenere una corretta fissazione durante la guida. Per identificare le caratteristiche dei soggetti più predisposti alle alte prestazioni di guida e quelle degli atleti di alto livello, abbiamo utilizzato il Visual Exploration Training System. Abbiamo studiato con test saccadici e attentivi vari gruppi di conducenti ordinari, di piloti professionisti, di camionisti professionisti e di altri atleti professionisti. I maschi hanno un tempo di reazione più veloce rispetto alle femmine e l'età inferiore ai 30 anni sembra garantire una migliore precisione delle prestazioni e nel raggiungere tutti gli obiettivi visivi. L'effetto dell'attività fisica e lo sport sono confermati. Le performance degli allievi selezionati della Ferrari Driver Academy sono significativamente migliori, in particolare rispetto al gruppo di aspiranti studenti e piloti dilettanti, probabilmente grazie alla predisposizione individuale e sulla cosiddetta 'efficienza neurale' dovuta sia ad un utilizzo ridotto delle risorse che al miglioramento nell'elaborazione delle informazioni, grazie a una migliore comunicazione tra le aree del cervello correlate alle attività.

PAROLE CHIAVE: Saccadi $\bullet$ Guida $\bullet$ Piloti sportivi $\bullet$ Eye-tracking $\bullet$ Sportivi di alto livello

\section{Introduction}

Driving is not only a physical task, but is also a mental task.

Our behaviour while driving depends from various factors: external non-modifiable elements (e.g. weather), external modifiable elements (mechanical equipment) and those dependent on our body (physical characteristics, psychological and adaptive factors). We live in a multi-sensorial environment: visual information (such as objects, persons, animals, buildings, locations), acous- tic information (like sounds, voices, noises), vestibular information from the labyrinths (like linear and angular acceleration, head position), proprioceptive information (body position) and tactile information (skin perception of posture and movement) are fundamental for adaptive programs to every environmental condition.

Many subjective cognitive processes, like attention, memory, learning, motivation, decision and psychological factors, are able to influence information processing and the ability to adapt quickly to modifications. Human errors such as misperception, information processing errors and 
poor decision making are frequently identified as causes of accidents ${ }^{1-5}$.

Visual inputs are indispensable in scanning the road, communicating with other road users and monitoring in-vehicle devices. The probability to detect an object while driving (conspicuity) is very important for assessment of driving effectiveness, and correct choice of information relevant to the safety of driving determines efficiency of a driver.

Accordingly, eye fixation and eye movements are essential for attention and choice in decision making ${ }^{6-9}$.

The main goal of eye movements is to maintain foveal control of the most important visual target in every static or dynamic condition, but drivers need to acquire relevant information using both central and peripheral vision, the so-called useful field of view (UFOV).

Various eye movements are used to perceive information in driving: smooth pursuit (SP), opticokinetic reflex (OKR), vestibulo-oculomotor reflex (VOR), vergence movements and saccadic movements (SM). These various systems are closely connected to control of the head (eyehead coordination mechanism) and total body movements (posture and gait control).

The eyes are never really fixed, because physiological micro-movement is continuous and has a nature of low-amplitude $\left(<1^{\prime}\right)$ and high-frequency vibrations $(50-100 \mathrm{~Hz})$. SM constitute the vast majority of ocular movements.

Saccadic Reaction Time (RT) exhibits temporal variability that is largely accounted for by the time necessary for visuo-motor and motor neurons to reach a specific threshold. The velocity is proportional to movement amplitude and reaches $900^{\circ} / \mathrm{sec}$ in humans. The saccade-generating system cannot respond to subsequent changes in the position of the target during eye movement and a second saccade must be made to correct the error. Any shift of gaze larger than about $20^{\circ}-30^{\circ}$ is accompanied by a head movement (so-called eye-head coordination). The head is moving at least $20-50 \mathrm{msec}$ later and the vestibulo-ocularreflex (VOR) causes the eyes to roll back in the head to keep gaze on the target.

SM may be reflexed or voluntary, peripherally-visually guided or centrally guided, and can be of various kinds. With regards to driving, the most important kind of saccades are the pro-saccades (reflexive saccade triggered exogenously by the appearance of a peripheral stimulus, or by the disappearance of a fixation stimulus), the scanning saccades (triggered endogenously for the purpose of exploring the visual environment), the anti-saccades (the eyes move away from the visual onset toward another direction), the memory guided saccade (the eyes move toward a remembered point, with no visual stimulus) and the predictive saccades (the eyes are kept on an object moving in a temporally and/or spatially predictive manner; saccades often coincide with or anticipate the predictable movement of an object).

Voluntary saccades are much more frequent in everyday life. A simple visually guided saccadic eye movement requires at least two mental processes: target selection and motor preparation. These processes are carried out by a network of cortical and subcortical structures ${ }^{10}{ }^{11}$. The frontal eye fields, parietal eye field, the motion-sensitive area (MT/V5), the precuneus (V6), and the angular and the cingulate gyri were more activated in reflexive saccades than in voluntary saccades. No significant difference in activation was found in the cerebellum. Working memory may be involved in anticipatory drifts ${ }^{12}$ and different cortical resources may be recruited when prediction is utilised, resulting in reduced latency, increased peak velocity and anticipatory movements. The cerebellum is crucial for synchronising saccades with learned or planned temporal events and the cerebellar vermis IV/V is involved in temporal prediction for saccadic movements. Usually antisaccadic responses show an increased latency and number of errors compared to prosaccadic response and the antisaccadic task also allows evaluation of the capacity to inhibit reflexive saccades and produce voluntary saccades. Its neuronal related network is still discussed ${ }^{13-15}$. To explore our environment, we make on average three saccades per second. Most of these saccades are of small amplitude $\left(<10^{\circ}\right.$ of visual angle) and in conjunction with head and or trunk movements ${ }^{16}$. Saccade motor control is highly stereotyped and automatised. Its long-term maintenance is served by an oculomotor learning process called saccadic adaptation which has to monitor success after the saccade and learn from observed errors in order to fine-tune planning parameters for future saccades ${ }^{17}$. The ability to generate antisaccades in the direction away from a new visual stimulus is fundamental in order to maintain an adequate level of attention. The antisaccade requires the capacity to inhibit a reflexive saccadic response in favour of complex volitional behaviour ${ }^{18-22}$. Saccadic movements can be trained and within half an hour healthy subjects become able to progressively improve saccadic control ${ }^{23-27}$. Activity in the inferior premotor cortex is significantly modulated and decreased during the progress of learning. Saccadic movements involve a problem of visual perception. During each, the visual scene sweeps across the retina with high-speed motion with inevitable blurring of the image, as the retina is sweeping the visual field. Object positions in retinal coordinates change, the entire visual image is not updated and humans become effectively blind, but usually we are not aware of this blur during eye movement. We do not perceive very fast disturbing motion or jumps of the 
visual scene because there is a mechanism that "cuts off" the processing of retinal images when it becomes blurred. This lack of perception or omission is linked to a phenomenon called masking or saccadic suppression ${ }^{28}$, which reduces the impact of retinal motion during the saccade on the visual system. This phenomenon is characterised by the inability to detect changes in the location of a target when the change occurs immediately before, during, or shortly after the saccade (120 msec). Because saccadic suppression starts before the actual onset of the saccade, it cannot be triggered by retinal motion and must be centrally activated by the brain. In this way, the cognitive individual system is able to reconstruct, "in real time", all the details of the retina caught in a glimpse, but not yet focused, through a "filling in" process. For this reason, the spatial reconstruction of the environment that surrounds us takes effect on a central level by comparing memorised past experiences ${ }^{29}$. However, each scene contains many different objects, few of which are relevant to behaviour at any given moment. Therefore, attentional mechanisms are also needed to select relevant objects. For this reason, the entire visual image is not updated during each saccade and large sudden changes in a visual scene can go undetected (change blindness).

Since the 1980s many authors have understood the important role of vision in driving and have measured eye movements, in daily practice, in sports, on heavy vehicles, at intersections without traffic lights, or in search of parking spaces, and have evaluated the effect of central de-structuring of eye movements due to alcohol intake ${ }^{30}$. There is evidence that the pattern of eye movements of the driver depends on the number of objects and on the complexity of the landscape ${ }^{3132}$ and on anticipation, which in turn depends on experience, and which can modify the reaction times. OKR is important while driving curves and at night, when solicitation of the peripheral retina is given by curbs, or, for instance, billboards, trees or tribunes. Too many optokinetic stimulations can be dangerous because of the large number of provoked saccadic phases. The angular VOR (from semicircular canals) makes a fundamental contribution to the maintenance of dynamic visual acuity while moving the head on horizontal and vertical planes. The linear VOR (from otolithic macular receptors) is very important during linear accelerations and decelerations. Unfortunately, the role of the substitutional SM which are typical of vestibular loss patient and which are able to increase the risk of saccadic visual suppression and blindness has not been evaluated.

However, saccades are the most widely used and effective means of maintaining a correct fixation while driving and the frequency of blinking, and saccade characteristics are a parameter to determine the level of fatigue and of attention ${ }^{33}$.
In the task of driving, saccades can be frequent and can be shorter than $200 \mathrm{msec}$.

Typically, drivers tend to fixate straight ahead when driving, usually towards the location where the vehicle will be in the next few seconds, at least on straight and undemanding roads. Drivers may adopt different search strategies when they need to perceive objects located in front of and behind their own car by using the rear and side mirrors or when they drive on a straight road (stable driving), and mainly perceive objects located in front of their own car with few mirror glances. The reflexions in the outside rear view mirror images, passing through doublegazed windows of the car, may provoke misperceptions. When approaching an intersection, drivers made repeated saccadic gaze movements; after entering the intersection, saccadic gaze movements are directed in the direction of turning. One of the most complex visual tasks when driving is exiting a multistory car park, which involves the scanning of hundreds of parked vehicles with an average fixation time of approximately $100 \mathrm{msec}$. The total time spent fixating on a likely hazardous vehicle is longer for people in the driving-only condition than for those talking on a mobile phone with less exploring saccades.

It can easily be argued that not looking in the right place almost certainly guarantees that drivers will not react to the risk appropriately. Common sense suggests that drivers should "keep their eyes on the road" and "look where they are going." During navigation, a driver tends to choose a target point in the field of view, allowing him/ her to anticipate direction of travel of the vehicle. This tendency can cause 2 types of conflict: emergence of a number of points that can be "target points" in the same visual task, or occurrence of a number of elements that could be important for driving, but related with a variety of other visual tasks, as pedestrian detection or visual control of navigation system. Car drivers can employ various visual strategies. The tangent point strategy is based on the use of the tangent point (TP). This is a point on the lane edge on the inside of the curve where the line of sight is tangential to the lane edge, and corresponds to the point in the driver's visual field where the visual orientation of the projection of the edge-line is reversed. The TP at a specific moment in time coincides with the apex point of a corner. The "gaze-sampling strategy" proposes to fixate points on the future path and measure the curvature of optic flow vectors, which can inform drivers whether they over- or under-steer and drivers direct their gaze on their future path, approximately 1 to $2 \mathrm{sec}$ ahead of the vehicle ${ }^{34}$. In general, the TP condition is preferred, and previewing the road curvature by tracking a distant point contributes to the stability of steering ${ }^{35}$. During daytime 
driving, visual distractions, such as billboards located on the roadside of a highway, increase the frequency of errors. Older people need more fixation than younger ones to follow the same scene, as well as more fixation to recognise the scene in circumstances of poor visibility (fog, rain, etc.). Furthermore, older people respond more slowly than younger people, they are less accurate in capturing scenes viewed while driving and make smaller saccades than young drivers ${ }^{36}$. The literature suggests that expert athletes do not differ from non-experts in elementary abilities such as visual acuity, colour vision, or peripheral response time ${ }^{37}$, but the former respond faster and more accurately to task-specific cues than non-experts 3839 . However, despite the extensive body of knowledge on the technological aspects of racecars, comparatively little is known about the motor, perceptual and cognitive skills of athlete performance in motorsports ${ }^{4041}$. Knowledge of these skills may aid in designing training methods for racing drivers and improve driver-vehicle interfaces for not only motorsport applications, but also road vehicles ${ }^{42} 43$. Both professional and naïve drivers may share the common knowledge necessary for ordinary road driving but driving a racing-car implies a number of additional skills, from the use of different controls to the management of braking and rapid accelerations.

It is well established that practice is a prerequisite for achieving high levels of performance ${ }^{44}$. Many studies have examined the effects of driving experience on eye movements using driving settings ${ }^{45}{ }^{46}$. During stable driving, eye movements are less variable in trained drivers than in untrained drivers ${ }^{47}$, and by varying driving conditions the difference becomes more evident. Experienced drivers seem to rely less on foveal vision and more on peripheral vision for steering control. Experienced or safer drivers seem to collect more information of the scene and to be able to move their locus of attention quicker than novices ${ }^{46}$. They also direct their gaze further ahead than novices. Horizontal scanning can be different. Experienced drivers tend to exhibit a wider horizontal search strategy with shorter eye-movement distances and longer fixation durations. On a dual-carriageway road, horizontal variances of fixation positions seem to be larger and fixation durations seem to be shorter in the experienced group than in the novice group; on a rural road experienced drivers seem to have smaller variances of fixation positions and longer fixation durations than novice drivers. Expert drivers are significantly more likely to gaze at areas of the roadway that contain information relevant to the reduction of risks than untrained drivers ${ }^{46-48}$. Their visual search depends on expectancy or anticipation skills based on experience. Therefore, the trained drivers may anticipate the locations where potential dangerous events and relevant objects are likely to appear. Those with better attentional function, as measured by avoidance of objects, exhibit faster and larger saccades when driving.

Advanced age hardly affects older drivers' ability to perceive hazards ${ }^{49}$. Novice drivers check the road more and estimate uninfluenced targets. They prioritise fixating on points on the road which aid steering, for example, "future path" points ${ }^{50}$ or fixate closer to the vehicle to maintain lane position. They also look more at side pavements for possible pedestrians stepping out, inspecting slippery roads more often for adjoining traffic or look around for possible undertaking or overtaking vehicles in more demanding situations. This type of visual behaviour is important because wider scanning may result in more peripheral hazards.

In simulated driving there are fewer significant differences in a spatial distribution of fixation points. The differences in visual strategy seem to be linked not only to experience (i.e., how long someone has driven), but also to expertise in a particular field (policemen, truck drivers, racing drivers). Through practice and experience, task performance improves when actions become more automated and there is less of a requirement for conscious intervention ${ }^{5152}$. With driving, it may be the case that through experience, fewer conscious resources are required to control the vehicle as driving skill becomes automatic and this frees up resources to allocate visual attention to other parts of the scene. At the tactical level, racing drivers show a different gaze strategy, adjusting their gaze as they drive through the corner and choose different driving lines and optimise their driving lines to increase corner exit speeds. However, racing drivers drive statistically significantly lower best lap times than non-racing drivers not only thanks to eye movements, but also to different eye-head coordination. The driver directs his gaze at a horizontal offset from the TP, and this offset is different for each corner, illustrating that the TP itself is not the main area of visual attention while driving through corners, but also with strong correlation between head rotation and the vehicle's rotational speed approximately one second later. The eyes-in-head angle remains relatively constant throughout the lap with large differences in the head yaw angle for racing drivers compared to nonracing drivers. Racing drivers turn their head nearly twice as often as non-racing drivers while cornering. Racing drivers also steer their head more into corners than non-racing drivers and vary their gaze direction as a function of traveled distance, whereas non-racing drivers keep a more constant gaze location, close to the vicinity of the TP. As racing drivers enter a corner, they direct their gaze away from the TP towards the outside of the corner, and as they progress 
through the corner they move their gaze towards the TP and beyond the TP. As the racing drivers exit the corner, they direct their gaze again towards the outside of the corner and subsequently look again towards the TP.

Brain functional studies have begun to indicate that skill acquisition in motor or cognitive domains may be associated with both increased or decreased response in taskrelated regions ${ }^{53-59}$. These findings suggest that neural efficiency may be associated with a greater automaticity and a reduced attentive load during task execution compared to 'ordinary' individuals ${ }^{6061}$.

Contextual cueing is a concept in psychology that refers to the manner in which the human brain gathers information from visual elements and their surroundings. It is defined as an attentional guidance or facilitation effect derived from past experiences of (mostly hidden) regularities of the (mainly visual) world. In other words, visual attention can be guided by incidentally acquired knowledge about spatial invariants. The attention decides to select or ignore the visual targets. Recent evidence collected in various highly skilled populations suggests that exceptional abilities, such as elite athletes, professional dancers, archers, divers and musicians, may be associated with specific changes in the morphological and functional architecture of the brain ${ }^{565962-78}$. Skills and expertise are accompanied by relevant brain functional modifications even in drivers, and a distinct brain functional organisation emerges even during relatively simple visuo-motor tasks. Just 2 hours of practice with a driving simulator are sufficient to induce structural changes ${ }^{79} 80$. Indeed, recent fMR studies ${ }^{81} 82$ showed both quantitative and qualitative differences between professional and naïve drivers. During the motor reaction, both naïve and professional drivers recruited similarly distributed networks (bilateral visual occipital, posterior temporal and parietal cortex, sensorimotor, motor and premotor areas, insula, striatum, cerebellum, cingulate, middle and inferior frontal cortex, prefrontal and precentral cortex, precuneus, parahippocampus, thalamus, lentiform nucleus), which include areas devoted to visuo-spatial processing, motor control and executive functions. However, comparative evaluation shows significant differences. Skilled car drivers are characterised by: reduced brain cortical activation and reinforced connectivity measures between task-relevant areas, consistent functional recruitment of driving-related brain regions (including vigilance, visuospatial monitoring, navigation, action preparation and motor control), increased grey matter density in basal ganglia, sensory-motor cortex, inferior frontal gyrus, retrosplenial cortex, fusiform/lingual gyrus and parahippocampus. Naïve car drivers are characterised by consistent modulation of brain response mostly limited to visual brain areas, and to regions devoted to spatial information processing, greater and more extensive response in supplementary motor area, left middle frontal and precentral cortex, bilateral inferior parietal lobule, right superior parietal, and postcentral cortex, cerebellum, and bilateral striatum and greater recruitment of task-related brain areas, including sensorimotor, parietal and prefrontal regions.

\section{Materials and methods}

In order to identify the features of the most predisposed subjects with high driving performances and those of high-level sportsmen, we used a special tool called Visual Exploration Training System (VET by SVEP) which consists in: personal computer (PC), eye-tracking system (120 Hz frequency analysis) and a new specific software by SVEP, according to the literature on the subject ${ }^{30}$.

We examined 174 subjects:

- group 1 (FDA): 6 Ferrari Driver Academy (FDA) students; 6 males (M) aged 15 to 20 years (mean $17.2 \pm$ 2.17);

- group 2 (ARD): 20 FDA aspiring students and amateur racing drivers; $19 \mathrm{M}$ and 1 females $(\mathrm{F})$ aged 14 to 27 years (mean $22.07 \pm 5.23$ );

- $\quad$ group 3 (PRD): 7 past professional racing drivers; $7 \mathrm{M}$ aged 36 to 55 years (mean $42.83 \pm 7.13$ );

- group 4 (BVP): 35 professional basket and volley ball players (Italian top league); $22 \mathrm{M}$ and $13 \mathrm{~F}$ aged 19 to 32 years (mean $23.43 \pm 5.27$ );

- $\quad$ group 5 (ORD): 87 ordinary road drivers; $58 \mathrm{M}$ and 29 $\mathrm{F}$, aged 15 to 53 years (mean $33.92 \pm 10.16$ );

- group 6 (PTD): 19 professional truck drivers; 19 M aged 35 to 47 years (mean $41.35 \pm 4.73$ ).

Both FDA-selected students and FDA-aspiring students as well as amateur racing drivers had prior experience in go-kart races and/or international high level races with different types of cars.

No participant had any history of balance disorder or asymmetric deficits of auditory or visual function. None was taking any medication.

Subjects were seating in front of a monitor wearing the eye-tracking system.

Two tests were performed.

In the first test (saccade test; ST), the subject had to fix a target point that appeared randomly on the monitor in 31 different positions in $23 \mathrm{sec}$.

We evaluated:

1. average start time (msec) of ocular movements, defined as the interval of time between the presentation of the stimulus appearance and start of appropriate response in the subject (RT); 
2. target reaching time (msec) with $80 \%$ accuracy (TRT);

3. average percentage of accuracy in achieving all targets (AP1).

In this way we evaluated the ability to produce repeated saccades for random stimuli maintaining a high level of attention.

In the second test (attentional test; AT), the subject had to maintain fixation on a target point that appeared randomly on the monitor in 50 different positions in $50 \mathrm{sec}$ even during the recurrent appearance of new distracting images (car, humans, animals, road-signals). The distractive images progressively increased in number (from 1 to 4 ) and type every $10 \mathrm{sec}$.

A possible saccade towards the distracting image requires a corrective antisaccade, which is more difficult to perform compared to a prosaccadic task. Given the greater difficulty of this task with respect to prosaccadic tasks, heightened control is needed for its success.

We evaluated:

1. number of centred target points or precision of performance (PP);

2. number of saccades not directed towards the target point or attention deficit index (ADI);

3. average percentage of accuracy in achieving all targets (AP2).

The study was developed according to Declaration of Helsinki for Ethical Principles for Medical Research In- volving Human Subjects of World Medical Association (WMA). All participants were volunteers and were informed about the study procedures and risks involved. All participants retained the right to withdraw from the study at any moment.

\section{Results}

Average start time (RT) for the series of 31 random reflexive saccades was shorter in FDA and in BVP (Table I). Target reaching time with $80 \%$ accuracy (TRT) was shorter in FDA, ARD and BVP. The average percentage of accuracy in achieving all targets (API) was higher in FDA, ARD and BVP. The highest number of centred target points or rather precision of performance in AT(PP) was in FDA and the lowest was in PTD.

Average percentage of accuracy in achieving all targets (AP2) was higher in FDA, ARD, PRD and BVP.

In AT, there were no significant differences between groups regarding the number of saccades not directed towards the right target point or attention deficit index (ADI).

The subjects aged less than 30 years (Table II) showed significantly better values for the target reaching time, with $80 \%$ accuracy (TRT) in ST and for the number of centred target points (PP) and for average percentage of accuracy in achieving all targets (AP2) in AT.

Table I. Mean and sd of the various parameters in ST and AT in various groups and significant differences ( $\mathrm{p}$ t-test) between ordinary road drivers (ORD) and other groups.

\begin{tabular}{|c|c|c|c|c|c|c|}
\hline & RT (msec) & TRT (msec) & AP1 & $\mathrm{PP}(\mathrm{N})$ & ADI (N) & AP2 \\
\hline FDA & 238.0 - sd 32.2 & 337.5 - sd 7.7 & 74.8 - sd 1.0 & 50.5 - sd 0.7 & 39.3 - sd 10.3 & 69.0 - sd 3.5 \\
\hline ARD & 268.3 - sd 31.3 & 380.0 - sd 29.6 & 65.9 - sd 7.7 & $44.0-\mathrm{sd} 4.6$ & 50,3 - sd 32.5 & 65.2 - sd 3.5 \\
\hline PRD & 257.0 - sd 35.8 & 410.7 - sd 28.0 & 64.4 - sd 5.5 & $44.8-s d 3.1$ & 37,7 - sd 5.2 & $66.5-\mathrm{sd} 3.1$ \\
\hline BVP & 252.4 - sd 24.6 & 339.7 - sd 26.3 & 70.2 - sd 5.9 & 45.6 - sd 4.4 & 48.9 - sd 14.7 & 67.6 - sd 4.6 \\
\hline ORD & 285.7 - sd 39.4 & 423.7 - sd 39.0 & $61.5-\mathrm{sd} 8.2$ & 45.0 - sd 5.9 & 45.8 - sd 21.3 & $61.0-\mathrm{sd} 7.0$ \\
\hline PTD & 299.1 - sd 31.1 & 423.7 - sd 25.8 & $62.7-\mathrm{sd} 6.2$ & 42.9 - sd 4.1 & 54.8 - sd 17.9 & $63.2-\mathrm{sd} 4.4$ \\
\hline ORD/FDA & 0.0047 & 0.0000 & 0.0002 & 0.0001 & & 0.0069 \\
\hline ORD/ARD & & 0.0000 & 0.0309 & 0.0002 & & 0.0106 \\
\hline ORD/PRD & & & & 0.0033 & & 0.0428 \\
\hline ORD/BVP & 0.0000 & 0.0000 & 0.0000 & & & 0.0000 \\
\hline ORD/PTD & & & & 0.0001 & & \\
\hline
\end{tabular}

Table II. Mean and sd of the various parameters in ST and AT of ordinary road drivers groups (ORD) aged less (29 cases) or more (58 cases) than 30 years.

\begin{tabular}{lcccccc} 
& RT $(\mathrm{msec})$ & TRT $(\mathrm{msec})$ & AP1 & PP (N) & ADI (n) & AP2 \\
ORD $<30 y$ & $284.55-\mathrm{sd} 36.39$ & $367.11-\mathrm{sd} 42.76$ & $61.5-\mathrm{sd} 8.2$ & $48-\mathrm{sd} 5.89$ & $40.62-\mathrm{sd} 25.17$ & $64.8-\mathrm{sd} 5.16$ \\
$\mathrm{ORD}>30 \mathrm{y}$ & $284.11-\mathrm{sd} 38.20$ & $387.45-\mathrm{sd} 35.22$ & $61.6-\mathrm{sd} 8.3$ & $43,38-\mathrm{sd} 5.11$ & $48.66-\mathrm{sd} 18.37$ & $58.8-\mathrm{sd} 7.04$ \\
$\mathrm{t}$-test & & 0.0205 & & 0.0006 & 0.0001 \\
\hline
\end{tabular}


In ordinary road drivers, there were differences between males and females. RT was slightly longer in females than in males (Table III). The number of saccades not directed towards the target point, i.e. the attention deficit index (ADI) was significantly higher in females and was associated with a lower average percentage of accuracy in achieving all targets (AP2).

This likely indicates a greater number of antisaccades in order to achieve all the correct targets.

The difference in number of saccades not directed towards the target point (ADI) was more significant in subjects aged less than 30 years: males made many fewer exploring saccades than females (Table IV). However, in this range of age the average accuracy in achieving all targets (AP2) was greater in females.

There were significant differences between ordinary road drivers and sports subjects (Table I). The average start time (RT) was shorter in FDA and in BVP.

Target reaching time with $80 \%$ accuracy (TRT) was shorter in FDA, ARD and BVP.

In ST, average percentage of accuracy in achieving all tar- gets (API) was higher in FDA, ARD and BVP and in AT (AP2) in FDA, ARD, PRD and BVP.

Both males (Table V) and females among professional basket and volley ball players showed better performance in the tests, and the female disadvantage was almost completely reduced by practice. The number of saccades not directed towards the target point (ADI) in AT was higher in females.

A probable difference also emerges due to individual predisposition. Indeed, in our tests the performances of FDAselected students were significantly better than those of the group of aspiring students and amateur racing drivers (ARD) (Table VI).

\section{Discussion}

The level of attention and collaboration was high in all groups. Indeed, in the AT there were no significant differences between groups regarding the number of saccades not directed towards the right target point or attention deficit index (ADI).

Table III. Mean and sd values of the various parameters in ST and AT in 58 males (M) and 29 females (F) of ordinary road drivers groups (ORD).

\begin{tabular}{|c|c|c|c|c|c|c|}
\hline & RT (msec) & TRT (msec) & AP1 & PP (NJ) & ADI (N) & AP2 \\
\hline F ORD & 294.17- sd 39.19 & 381.13 - sd 42.24 & 62.0 - sd 9.9 & 46.18 - sd 3.40 & 52.5 - sd 25.66 & 59.0 - sd 8.11 \\
\hline M ORD & 277.88 - sd 34.76 & 378.31 - sd 35.45 & $61.5-\mathrm{sd} 7.3$ & 44.74- sd 6.05 & 40.76 - sd 15.90 & $62.5-\mathrm{sd} 5.72$ \\
\hline t-test & 0.0516 & & & & 0.0102 & 0.0222 \\
\hline
\end{tabular}

Table IV. Mean and sd of the various parameters in ST and AT in 21 males (M) and 8 females ( $\mathrm{F}$ ) of ordinary road drivers groups (ORD) aged less than 30 years.

\begin{tabular}{|c|c|c|c|c|c|c|}
\hline & RT (msec) & TRT (msec) & AP1 & $\mathrm{PP}(\mathrm{n})$ & ADI (N) & AP2 \\
\hline $\mathrm{FORD}<30$ y & 278.46 - sd 41.12 & 358.0 - sd 41.15 & $67.7-\mathrm{sd} 7.1$ & 47.71 - sd 2.45 & 64.37 - sd 37.59 & 68.6 - sd 5.61 \\
\hline$M O R D<30 y$ & 283.75 - sd 24.59 & 366.0 - sd 19.69 & $63.6-\mathrm{sd} 3.0$ & 48.09 - sd 6.67 & 31.57 - sd 8.99 & 63.2 - sd 4.3 \\
\hline t-test & & & 0.0349 & & 0.0007 & 0.0098 \\
\hline
\end{tabular}

Table V. Mean and sd of the various parameters in ST and AT in 58 males (M) ordinary road drivers (ORD) and 22 of professional players group (BVP) and in 29 females (F) ordinary road drivers and 13 of professional players group (BVP).

\begin{tabular}{|c|c|c|c|c|c|c|}
\hline & RT (msec) & TRT (msec) & AP1 & $\mathrm{PP}(\mathrm{N})$ & ADI (N) & AP2 \\
\hline M ORD & 277.88 - sd 34.76 & $378.31-$ sd 35.45 & $61.5-\mathrm{sd} 7.3$ & $44.74-$ sd 6.05 & 40.76 - sd 15.90 & $62.5-\operatorname{sd} 5.72$ \\
\hline M BPV & $252.2-\mathrm{sd} 27.3$ & 345.2 - sd 26.2 & $69.1-\operatorname{sd} 6.2$ & $45.9-\mathrm{sd} 3.8$ & 44.9 - sd 10.7 & $67.2-\mathrm{sd} 4.4$ \\
\hline t-test M BPV/ORD & 0.0026 & 0.0002 & 0.0000 & & & 0.0008 \\
\hline F ORD & 294.17 - sd 39.19 & 381.13 - sd 42.24 & 62.0 - sd 9.9 & $46.18-\mathrm{sd} 3.40$ & 52.5 - sd 25.66 & 59.0 - sd 8.11 \\
\hline F BPV & 252.8 - sd 20.1 & 330.3 - sd 24.5 & 72.1- sd 5.0 & 45.4 - sd 5.3 & 54.6 - sd 18.0 & $68.4-$ sd 4.8 \\
\hline t-test F BPV/ORD & 0.0009 & 0.0002 & 0.0033 & & & 0.0004 \\
\hline F BPV & 252.8 - sd 20.1 & $330.3-\mathrm{sd} 24.5$ & 72.1 - sd 5.0 & 45.4 - sd 5.3 & 54.6 - sd 18.0 & $68.4-\mathrm{sd} 4.8$ \\
\hline $\begin{array}{l}\text { M BPV } \\
\text { t-test M/F BVP }\end{array}$ & 252.2 - sd 27.3 & 345.2 - sd 26.2 & $69.1-\mathrm{sd} 6.2$ & $45.9-\mathrm{sd} 3.8$ & $\begin{array}{c}44.9-\text { sd } 10.7 \\
0.0429\end{array}$ & $67.2-\mathrm{sd} 4.4$ \\
\hline
\end{tabular}


Table VI. Mean and sd of various parameters in ST and AT in males (M) aged less than 30 years: 6 of Ferrari Driver Academy (FDA), 21 ordinary road drivers (ORD) and 19 aspiring students and amateur racing drivers (ARD).

\begin{tabular}{lcccccc} 
& RT $(\mathrm{msec})$ & TRT $(\mathrm{msec})$ & AP1 & PP $(\mathrm{N})$ & ADI $\left(\mathrm{n}^{\circ}\right)$ & AP2 \\
FDA & $238.0-\mathrm{sd} 32.2$ & $337.5-\mathrm{sd} 7.7$ & $74.8-\mathrm{sd} 1.0$ & $50.5-\mathrm{sd} 0.7$ & $39.3-\mathrm{sd} \mathrm{10.3}$ & $69.0-\mathrm{sd} 3.5$ \\
ARD & $268.3-\mathrm{sd} 31.3$ & $380.0-\mathrm{sd} 29.6$ & $65.9-\mathrm{sd} 7.7$ & $44.0-\mathrm{sd} 4.6$ & $50.3-\mathrm{sd} \mathrm{32.5}$ & $65.2-\mathrm{sd} 3.5$ \\
t-test FDA/ARD & 0.0047 & 0.0000 & 0.0002 & 0.0025 & 0.0005 & 0.0069 \\
\hline
\end{tabular}

Usually the mean reaction time to detect visual stimuli and to produce a reactive saccade is approximately 180-200 msec. Reaction time shortens with age through childhood and gradually lengthens during adulthood; it also depends on attention and inter-individual variability is evident ${ }^{83}$. However, the values remained stable in the age range of our study. Probably in our examination conditions RT in ST (Table I) was higher depending on the particular conditions of examination. In fact, we evaluated the average time for a long series of 31 random reflexive saccades. In agreement with the literature, in our study males had faster RT as compared to females. The age below 30 seems to guarantee better target reaching time (TRT), precision of performance (PP) and accuracy in achieving all targets (AP2). The effect of physical activity and doing sports on improving RT and accuracy in achieving all visual targets is confirmed.

The performances of females professional players are better compared with female ordinary road drivers and in our study the female disadvantage was almost completely reduced by practice ${ }^{84-87}$. The performances of professional truck drivers were similar to those of ordinary road drivers, but were also characterised by lower precision of performance in the ST. These performances are significantly worse compared with those of racing drivers of the same age. Likely this is related to the problem of driving tasks. In driving, many tasks are performed and drivers may adopt different search strategies depending on the current driving task. For example, when drivers are passing, they need to perceive objects located in front of and behind their own car by using rear and side mirrors in preparation for maneuvering. In contrast, when drivers drive on a straight road (stable driving), they perceive mainly objects located in front of their own car with few mirror glances. Large vehicles only have side mirrors and therefore require different visual control strategies. In fact, it has been shown that the number of gaze movements was significantly greater in drivers of large vehicles. The amplitude of eye movements is significantly broader when driving large vehicles (truck, bus) than during driving a small car.

Finally, the performances of FDA-selected students were significantly better than those of the group of aspiring students and amateur racing drivers probably thanks to individual predisposition based on so-called 'neural efficiency', which postulates more efficient cortical functioning based on both a reduced utilisation of resources and an improvement in information processing, thanks to a better communication between task-related brain areas. Indeed, selected populations of individuals achieve very high levels of skills and performance in fields ranging from arts to sport activities as a consequence of intensive training and, probably, of some genetic predisposition ${ }^{72}$. However, the role of genetic predisposition and/or of acquired experience is not yet clear.

\section{Conclusions}

Both professional and naïve drivers may share the common knowledge necessary for ordinary road driving, but naïve individuals simply watch the race, while professional drivers imagine themselves to race.

In order to improve both safety and performances during daily or sports driving, it is important "what and where to look". Visual environmental control requires that foveal vision is maintained on specific targets (reference objects, trajectory points) and experience aimed at creating specific neuronal networks able to satisfy the most appropriate eye-test-body motor control strategy.

Indeed, the sensory-motor decision processes interact via functional information-processing loops in the brain to produce complex, adaptive behaviours ${ }^{88}$. To achieve this goal, it is necessary to maintain adequate levels of visual attention even in the presence of distracting targets, reduce saccadic movements (with relative blindness and possible loss of environmental information from sections of the route that increase with increasing speed) and train the ability to perform eventual corrective antisaccades.

These abilities are essential for any high-level sporting activity, particularly for drivers. Athletic men and women acquire these performances with experience and training. The acquired attentional capacity tends to remain high even over time, mostly in racing drivers. Women generally show lower level performances, but they can significantly improve with training. The gaze is considered a good method of evaluation for assessment of attention 
while driving ${ }^{89}$ and a correct strategy of visual control of the environment through saccadic and anti-saccadic movements adapted to the situation is of fundamental importance in sport and driving. Our easy-to-use diagnostic method seems to be able to identify the most predisposed subjects at high driving performances and thus those to be submitted to specific training ${ }^{45}$ to improve the function of saccadic exploration and safety in driving.

\section{Acknowledgements}

The authors thank Massimo Rivola (Head of Ferrari Driver Academy, Maranello, Italy) for allowing us to examine his drivers; Autodromo di Modena, Pallacanestro Reggiana, Volley Tricolore Reggio Emilia, Liu Jo Volley Modena and Pallacanestro Mantovana for their collaboration; SVEP srl for technological support; all study participants for their availability.

\section{Conflict of interest statement}

None declared.

\section{References}

1 Zhang Y, Kaber DB, Rogers M, et al. The effects of visual and cognitive distractions on operational and tactical driving behaviors. Hum Factors 2014; 56:592-604.

2 Lee JD, Regan MA,Young KL. Defining driver distraction. In: Regan MA, Lee J D, Young KL, editors. Driver Distraction: Theory, Effects, and Mitigation. Boca Raton, FL: CRC Press; 2008. pp. 31-40.

3 Borowsky A, Horrey WJ, Liang Y et al. Effects of brief visual interruption tasks on drivers' ability to resume their visual search for a pre-cued hazard. Accid Anal Prev 2016; 93: 207-16.

4 Liang Y, Lee JD Combining cognitive and visual distraction: less than the sum of its parts. Accid Anal Prev 2010;42:881-90.

5 White CB, Caird JK. The blind date: the effects of change blindness and gender on looked-but -failed-to-see (LBFTS) errors. Accid Anal Prev 2010;42:1822-30.

6 Orquin JL, Mueller Loose S. Attention and choice: a review on eye movements in decision making. Acta Psychol (Amst) 2013;144:190-206.

7 Underwood G, Crundall D, Chapman P. Driving simulator validation with hazard perception. Transp Res Part F Traffic Psychol Behav 2011;14; 435-46.

8 Marquart G, Cabrall C, de Winter J. Review of eye-related measures of drivers' mental workload. Procedia Manuf 2015;3:32854-61.

9 Wieser MJ, Pauli P, Mühlberger A. Probing the attentional control theory in social anxiety: an emotional saccade task. Cogn Affect Behav Neurosci 2009;9:314-22.

10 Schraa-Tam CK, van Broekhoven P, van der Geest JN, et al. Cortical and cerebellar activation induced by reflexive and voluntary saccades. Exp Brain Res 2009;192:175-87.

11 Alvarez TL, Alkan Y, Gohel S, et al. Functional anatomy of predictive vergence and saccade eye movements in humans: a functional MRI investigation. Vision Res 2010;50:2163-75.
12 Curtis CE. Prefrontal and parietal contributions to spatial working memory. Neuroscience 2006;139:173-80.

13 Cutsuridis V. Behavioural and computational varieties of response inhibition in eye movements. Philos Trans R Soc Lond, B, Biol Sci 2017;372:20160196.

14 Aponte EA, Schobi D, Stephan KE, et al. The Stochastic Early Reaction, Inhibition, and late Action (SERIA) model for antisaccades. PLoS Comput Biol 2017;13:e1005692.

15 Cordones I, Gomez CM, Escudero M. Cortical dynamics during the preparation of antisaccadic and prosaccadic eye movements in humans in a gap paradigm. PLoS ONE 2013;8:e63751.

16 Starke SD, Baber C, Cooke NJ, et al. Workflows and individual differences during visually guided routine tasks in a road traffic management control room. Appl Ergon 2017;61:79-89.

17 Pélisson D, Alahyane N, Panouillères M, et al. Sensorimotor adaptation of saccadic eye movements. Neurosci Biobehav Rev 2010;34:1103-20.

18 Dyckman KA, Camchong J, Clementz B, et al. An effect of context on accade-related behavior and brain activity. Neuroimage 2007;36:774-84.

19 Hwang K, Velanova K, Luna B. Strengthening of top-down frontal cognitive control networks underlying the development of inhibitory control: a functional magnetic resonance imaging effective connectivity study. J Neurosci 2010;30:15535-45.

20 Jamadar SD, Johnson BP, Clough M, et al. Behavioral and neural plasticity of ocular motor control: changes in performance and fMRI activity following antisaccade training. Front Hum Neurosci 2015;9:1-13.

21 Ettinger U, Ffytche DH, Kumari V, et al. Decomposing the neural correlates of antisaccade eye movements using event-related fMRI. Cereb Cortex 2008;18:1148-59.

22 Unsworth N, Spillers GJ, Brewer GA, et al. Attention control and the antisaccade task: a response time distribution analysis. Acta Psychol 2011;137:90-100.

23 Findlay JM, Hazel IB. Saccade target selection: do distractors affect saccade accuracy? Vision Res 2009;49:1267-74.

24 Leong DF, Master CL, Messner LV, et al. The effect of saccadic training on early reading fluency. Clin Pediatr (Phila) 2014;53:858-64.

25 Jiang YV, Won BY, Swallow KM. First saccadic eye movement reveals persistent attentional guidance by implicit learning. J Exp Psychol Hum Percept Perform 2014;40:1161-73.

26 Buonocore A, McIntosh RD. Modulation of saccadic inhibition by distractor size and location. Vision Res 2012;15:32-41.

27 Kleiser R, Stadler C, Wimmer S, et al. An fMRI study of training voluntary smooth circular eye movements. Exp Brain Res 2017;235:819-31.

28 Ibbotson MR, Crowder NA, Cloherty SL, et al. Saccadic modulation of neural responses: possible roles in saccadic suppression, enhancement and time compression. J Neurosci 2008;28:10952-60.

29 Elliot MA. Predicting motorcyclists' intentions to speed: effects of selected cognitions from the theory of planned behaviour, self-identity and social identity. Accid Anal Prev 2010;42:718-25.

30 Kapitaniak B, Walczak M, Kosobudzki M, et al. Application of eyetracking in drivers testing: a review of research. Int J Occup Med Environ Health 2015;28:941-54.

31 Antonson $\mathrm{H}$, Ahlström C, Mårdh S, et al. Landscape heritage objects' effect on driving: a combined driving simulator and questionnaire study. Accid Anal Prev 2014;62:168-77.

32 Seya Y, Nakayasu H, Yagi T. Useful field of view in simulated driving: Reaction times and eye movements of drivers. i-Perception 2013;4:285-98. 
33 Schleicher R, Galley N, Briest S, et al. Blinks and saccades as indicators of fatigue in sleepiness warnings: looking tired? Ergonomics 2008;51:982-1010.

34 Elliott MA, Thompson JA. The social cognitive determinants of offending drivers' speeding behavior. Accid Anal Prev 2010;42:1595-605.

35 Kandl FI, Rotter A, Lappe M. Car drivers attend to different gaze targets when negotiating closed vs. open bends. J Vis 2010;10:1-11.

36 Lee SS, Wood JM, Black AA. Blur, eye movements and performance on a driving visual recognition slide test. Ophthalmic Physiol Opt 2015;35:522-9.

37 Memmert D, Simons DJ, Grimme T. The relationship between visual attention and expertise in sports. Psychol Sport Exerc 2009;10: 146-51.

38 Mann DTY, Williams AM, Ward P, et al. Perceptual-cognitive expertise in sport: a meta-analysis. J Sport Exerc Psychol 2007;29: 457-78.

39 Aglioti SM, Cesari P, Romani M, et al. Action anticipation and motor resonance in elite basketball players. Nat Neurosci 2008;11:1109-16.

40 Owen N, King H, Lamb M. Literature review of race driver fatigue measurement in endurance motorsport. Procedia Eng 2015;112: 344-8.

${ }^{41}$ Potkanowicz ES, Mendel RW. The case for driver science in motorsport: A review and recommendations. Sports Med 2013;43:565-74.

42 Baldisserri L, Bonetti R, Pon F, et al. Motorsport driver workload estimation in dual task scenario: a methodology for assessing driver workload in a racing simulator. $6^{\text {th }}$ International Conference on Advanced Cognitive Technologies and Applications. IARIA; 2014. pp. 56-61.

43 Lappi O. The racer's brain how domain expertise is reflected in the neural substrates of driving. Front Hum Neurosci 2015;9:635.

44 van Leeuwen PM, de Groot S, Happee R, et al. Differences between racing and non-racing drivers: a simulator study using eye-tracking. PLoS ONE 2017;12:e186871.

45 Guidetti G, Rigo S, Livio S, et al. Oculomotor training and driving performances. Med Sport 2011;64:409-22.

46 Kostantopoulos P, Chapman P, Crundall D. Driver's visual attention as a function of driving experience and visibility. Using a driving simulator to explore drivers' eye movements in day, night and rain driving. Accid Anal Prev 2010;42:827-34.

47 Seya Y, Nakayasu H, Patterson P. Visual search of trained and untrained drivers in a driving simulator. J Psychiatr Res 2008;50:242-52.

48 Alberti CF, Shahar A, Crundall D. Are experienced drivers more likely than novice drivers to benefit from driving simulations with a wide field of view? Transp Res Part F Traffic Psychol Behav 2014;27:124-32.

49 Pradhan AK, Pollatsek A, Knodler M, et al. Can younger drivers be trained to scan for information that will reduce their risk in roadway traffic scenarios that are hard to identify as hazardous? Ergonomics 2009;52:657-73.

50 Borowsky A, Shinar D, Oron-Gilad T. Age, skill, and hazard perception in driving. Accid Anal Prev 2010;42:1240-9.

51 Kountouriotis G K, Floyd RC, Gardner $\mathrm{PH}$, et al. The role of gaze and road edge information during high-speed locomotion. J Exp Psychol Hum Percept Perform 2012;38:687-702.

52 Lappi O. Future path and tangent point models in the visual control of locomotion in curve driving. J Vis 2014;14:21.

53 Reithler J, van Mier HI, Goebel R. Continuous motor sequence learning: cortical efficiency gains accompanied by striatal functional reorganization. Neuroimage 2010;52:263-76.
54 Gobel EW, Parrish TB, Reber PJ. Neural correlates of skill acquisition: Decreased cortical activity during a serial interception sequence learning task. Neuroimage 2011;58:1150-7.

55 Milton J, Solodkin A, Hlustík P, et al. The mind of expert motor performance is cool and focused. Neuroimage 2007;35:804-13.

56 Chang Y, Lee JJ, Seo JH, et al. Neural correlates of motor imagery for elite archers. NMR Biomed 2011;24:366-72.

57 Baumeister J, Reinecke K, Liesen H, et al. Cortical activity of skilled performance in a complex sports related motor task. Eur J Appl Physiol 2008;104:625-31.

58 Del Percio C, Infarinato F, Iacoboni M, et al. Movement-related desynchronization of alpha rhythms is lower in athletes than non-athletes: a high-resolution EEG study. Clin Neurophysiol 2010;121:482-91.

59 Nakata H, Yoshie M, Miura A, et al. Characteristics of the athletes' brain: evidence from neurophysiology and neuroimaging. Brain Res Rev 2010;62:197-211.

60 Andrews-Hanna JR, Reidler JS, Sepulcre J, et al. Functionalanatomic fractionation of the brain's default network. Neuron 2010;65:550-62.

61 Buckner RL, Andrews-Hanna JR, Schacter DL. The brain's default network: anatomy, function, and relevance to disease. Ann N Y Acad Sci 2008;1124:1-38.

62 Draganski B., May A. Training-induced structural changes in the adult human brain. Behav Brain Res 2008;192:137-42.

63 Roberts RE, Anderson EJ, Husain M. Expert cognitive control and individual differences associated with frontal and parietal white matter microstructure. J Neurosci 2010;30:17063-7.

${ }^{64}$ Wei G, Zhang, Y, Jiang T, et al. Increased cortical thickness in sports experts: a comparison of diving players with the controls. PLoS One 2011;6:e17112.

65 May A. Experience-dependent structural plasticity in the adult human brain. Trends Cogn Sci 2011;15:475-82.

66 Di Paola M, Caltagirone C, Petrosini L. Prolonged rock climbing activity induces structural changes in cerebellum and parietal lobe. Hum Brain Mapp 2013;34:2707-14.

67 Milton J, Solodkin A, Hlustik P, et al. The mind of expert motor performance is cool and focused. Neuroimage 2007;35:804-13.

68 Kim J, Lee HM, KimWJ, et al. Neural correlates of pre-performance routines in expert and novice archers. Neurosci Lett 2008;445:236-41.

69 Del Percio C, Babiloni C, Bertollo M, et al. Visuo-attentional and sensorimotor alpha rhythms are related to visuo-motor performance in athletes. Hum Brain Mapp 2009;30:3527-40.

70 Wei G, Luo J. Sport expert's motor imagery: functional imaging of professional motorskills ands implemotor skills. Brain Res 2010;1341:52-62.

71 Seo J, Kim YT, Song HJ, et al. Stronger activation and deactivation in archery experts for differential cognitive strategy in visuospatial working memory processing. Behav Brain Res 2012;229:185-93.

72 Yarrow K, Brown P, Krakauer JW. Inside the brain of an elite athlete: the neural processes that support high achievement in sports. Nat Rev Neurosci 2009;10:585-96.

73 Herholz SC, Zatorre RJ. Musical training as a framework for brain plasticity: behavior, function, and structure. Neuron 2012;76:486502.

74 Chang Y. Reorganization and plastic changes of the human brain associated with skill learning and expertise. Front Hum Neurosci 2014;8:35.

75 Kim YT, Seo, JH, Song HJ, et al. Neural correlates related to action observation in expert archers. Behav Brain Res 2011;223:342-7. 
G. Guidetti et al.

76 Del Percio C, Iacoboni M, Lizio R, et al. Functional coupling of parietal alpha rhythms is enhanced in athletes before visuomotor performance: a coherence electroencephalographic study. Neuroscience 2011;175:198-211.

77 Rypma B, Prabhakaran V. When less is more and when more is more: the mediating roles of capacity and speed in brain-behavior efficiency. Intelligence 2009;37:207-22.

78 Abreu AM, Macaluso E, Azevedo RT, et al. Action anticipation beyond the action observation network: a functional magnetic resonance imaging study in expert basketball players. Eur J Neurosci 2012;35:1646-54.

79 Sagi Y, Tavor I, Hofstetter S, et al. Learning in the fast lane: new insights into neuroplasticity. Neuron 2012;73:1195-203.

80 Assaf Y, Pasternak O. Diffusion tensor imaging (DTI)-based white matter mapping in brain research: a review. J Mol Neurosci 2008;34:51-61.

81 Bernardi G, Ricciardi E, Sani L, et al. How skill expertise shapes the brain functional architecture: an fMRI study of visuo-spatial and motor processing in professional racing-car and naïve drivers. PLoS One 2013;18:e77764.

82 Patel R, Spreng RN, Turner GR. Functional brain changes following cognitive and motorskills training: a quantitative meta-analysis. Neurorehabil Neural Repair 2013;27:187-99.
83 Maruta J, Spielman LA, Rajashekar U, et al. Visual tracking in development and aging. Front Neurol 2017;8:640.

84 Lipps DB, Galecki AT, Ashton-Miller JA. On the implications of a sex difference in the reaction times of sprinters at the Beijing olympics. PLoS One 2011;6:e26141.

85 Dykiert D, Der G, Starr JM, et al. Sex differences in reaction time mean and intraindividual variability across the life span. Dev Psychol 2012;48:1262-76.

86 Jain A, Bansal R, Kumar A, et al. A comparative study of visual and auditory reaction times on the basis of gender and physical activity levels of medical first year students. Int J Appl Basic Med Res 2015;5:124-7.

87 Ritesh MK, Tejas PG, Hemant BM, et al. Effect of gender difference on visual reaction time: a study on medical students of Bhavnagar Region. IOSR J Pharm 2012;3:452-4.

88 Kim TD, Kabir M, Gold JI. Coupled decision processes update and maintain saccadic priors in a dynamic environment. J Neurosci 2017;37:3632-45.

89 Hergeth S, Lorenz L, Vilimek R, et al. Keep your scanners peeled: gaze behavior as a measure of automation trust during highly automated driving. Hum Factors 2016;58:509-19.

Received: April 13, 2018 - Accepted: June 14, 2018

How to cite this article: Guidetti G, Guidetti R, Manfredi M, et al. Saccades and driving. Acta Otorhinolaryngol Ital 2019;39:186-196. https://doi.org/10.14639/0392-100X-2176

Address for correspondence: Giorgio Guidetti, Vertigo Center, Poliambulatorio Chirurgico Modenese, strada Morane 390, 41125 Modena, Italy. E-mail: giorgio.vertigine@gmail.com 